\title{
Four years of TJHE at a glance
}

\author{
Luigi F. Donà dalle Rose \\ Past Editor
}

Anna Serbati

Past Assistant Editor

doi: http://dx.doi.org/10.18543/tjhe-7(1)-2019pp19-22

As an answer to a kind invitation from the present Editor Prof Mary Gobbi, we dare to share as past TJHE Editors some reflections about our four-year period, which edited 8 issues out of a total of 12 issues since when the Journal was born (2013).

First of all, it has been a rewarding period of our academic life, for which Lupo is most grateful to Julia Gonzalez, who first approached him for this role and to the whole prestigious Editorial Board of those days. For Anna this experience represented a great learning and sharing opportunity, with a chance of being in contact with a worldwide community dealing with higher education challenges.

After four years, we must say we found the job easier than what we thought at the beginning. First of all, this was due to the solid and clear Journal foundations, as established by Paul Ryan, the founding Editor. But it was also in a large part due to the quite effective cooperation we received and enjoyed from the Managing Editor Ladislas Bizimana Kayinamura, a thread of continuity with the past, a careful and precious counsellor in many daily life issues and finally a rigorous "copyeditor". As Editor and Assistant Editor we combined different expertises. On the one side, Lupo offered his wide experience with the several players of the international academic community, with Tuning and with other international projects. On the other side, Anna offered her younger competence in educational sciences, joined to a direct knowledge of expert colleagues, who were often essential for a good paper hunting and a trustful review work. In a word, we experienced a most happy Editorial team, a cradle to improve our own team work competences.

The Directors of the Tuning Academy offered continuous mentorship about the editorial role and were inspiring sources of actions.

During our Editorial period, some relevant changes occurred in the Journal policy. The first decision was to accept for both annual issues any submissions within the scope of the Journal, without looking for a focused 
contribution in view of a pre-established thematic issue: since we were in the third publishing year, so still a quite young journal, and we needed submissions, this decision simplified the work at a large extent. As a consequence, the title of the two annual issues were usually found by the Editors ex-post. As a second fact, on a proposal of ours, the Editorial Board, which includes the Editorial team, was enlarged from 9 to 16 members, with an eye to gender parity and geographic distribution, the final members being from 15 countries and 5 continents. The main aim was to receive help in finding good authors/submissions: this occurred in some relevant cases. Thirdly, the description of the focus and scope of the Journal was made more detailed and transparent, i.e. more author-friendly and more open to nonTuning communities; this was achieved with a substantial help from the Editorial Board and the Advisory Editors' Panel. Finally, as Editors, we proposed to change the review process from the existing double-open mode to a double-blind mode. The double blind review process was adopted by the Editorial Board during its meeting on November 2017 and it was soon implemented, with some adjustments during the transition period. In order to assure originality of submissions, the Turnitin software was adopted, its results being subject to a responsible decision to be taken by the Editorial team. On the same November 2017 meeting of the Editorial Board, the panel of Advisory Editors was enriched with a number of quite cooperative reviewers.

Of course, as promised in our first Editorial, we continued the open access policy of the Journal and made "a continuing effort in order to qualify for ISI registration": the Journal was accepted for indexing by Scopus on September 2018 and by ESCI (WoS) on June 2019.

However, the policy issues, even though important, were only in the background of our daily wok. We soon learned how important was/is to prepare the forthcoming issue(s) well in advance, the key words in the early phase being "paper hunting" and "finding good reviewers". As to paper hunting, we sent out invitations to fellow colleagues all over the world to consider publishing their research work in our journal. An important number of submissions came from the Short-Term Visits Scholarship Scheme of Deusto International Tuning Academy. Finally, a most interesting source of new submissions was the incubator action promoted by the projects Tuning MEDA and Tuning Africa with their calls for "research Sessions". We are particularly proud of the large variety of authors, who came from very diverse areas of the world and from different disciplines, highlighting the interdisciplinary approach of TJHE, also outside the Tuning community. The articles discussed a wide range of topics: from political reflections to 
curriculum design and to specific methodologies in classroom. TJHE offers now a real platform to discuss HE challenges in a hopefully sustainable future.

As to the main content of the published articles, according to an assignment by inspection to the four general topics covered by our Journal, we find that after 12 issues (76 articles), $62 \%$ of the articles covers "Competence-based learning in higher education"; followed by $30 \%$ covering "Emergence and development of higher education areas", 7\% covering "Cooperation and partnership building", and only $1 \%$ - so far! - covering "Academic teachers' professional development and teaching competences".

Looking at the geographical coverage of the same articles, we find 9 articles (12\% of the total) which are general in scope, e.g. theoretically oriented, opening a debate, etc.. As to the others ( $88 \%$ of the total), they are concretely linked either to a regional area (32\%) or to one/more countries $(53 \%)$ or to both geographical contexts (4\%). The following Table gives the number of these coverages, as distributed among continents.

Table I

\begin{tabular}{|l|c|c|}
\hline \multirow{2}{*}{$\begin{array}{c}\text { TJHE Geographical } \\
\text { Coverage (after 12 issues) }\end{array}$} & \multicolumn{2}{|c|}{ Number of coverages related to: } \\
\cline { 2 - 3 } Africa & 8 & Country \\
\hline Asia & 2 & 15 \\
\hline Europe & 16 & 14 \\
\hline Oceania & 0 & 1 \\
\hline Latín America & 7 & 7 \\
\hline North America & 0 & 4 \\
\hline
\end{tabular}

Table comments: Out of a total of 76 published articles in the first 12 issues of TJHE, the articles involved in this table are 67, some of them covering more than one geographical context. As a whole 80 geographical contexts/situations are covered.

From the Table, we easily find that Europe accounts for $38 \%$ of the cumulated (i.e. regional plus country) coverages, followed by Africa (29\%), Latin America (18\%), Asia (10\%), North America (5\%) and Oceania (1\%). As a whole, the number of countries covered so far is 28 .

Finally, at June 2019, the numbers of submissions accepted for publication in TJHE since the Journal birth from authors belonging to either Tuning or 
non-Tuning research communities are almost similar (the "non-Tuning" articles being slightly more in number).

As to the content quality of the submissions, we acknowledge here once more the unique and irreplaceable work of the many reviewers who helped us. In our four-year period, as a whole about 135 reviewing tasks were carried out rigorously. Only in a limited number of cases, it was required a third reviewer. The rejection rate was $27 \%$. Within the double-open reviewing process, the Advisory Editors played quite a role helping in finding the reviewers and assuring originality. However, since the experienced refusal rate of potential AEs was rather high, when implementing the double blind procedure plus Turnitin originality check, we as Editors preferred to choose directly the reviewers, in order to save some time.

A special reflection regards the online tools available for the Editorial and reviewing work: according to our experience, a consistent group of authors as well as reviewers is still "afraid of pushing the journal platform buttons". In few cases, this was primarily due to adverse technological environments, but in other cases the Editorial team had to use some wisdom and real patience in order to get the submissions through. In these latter cases, ordinary e-mail exchange was the tool!

As a conclusion, we are extremely grateful to the Tuning Academy and to its loving and inspiring core of Founders and Directors, for the great opportunity they offered us in these last four years. To Mary Gobbi, the present Editor, we give, as our baton, the same words we received from Paul Ryan, when we started our work: "do bring TJHE to new Heights"! 


\title{
Four years of TJHE at a glance
}

\author{
Luigi F. Donà dalle Rose \\ Past Editor
}

Anna Serbati

Past Assistant Editor

doi: http://dx.doi.org/10.18543/tjhe-7(1)-2019pp19-22

\section{Copyright}

Copyright for this article is retained by the Publisher. It is an Open Access material that is free for full online access, download, storage, distribution, and or reuse in any medium only for noncommercial purposes and in compliance with any applicable copyright legislation, without prior permission from the Publisher or the author(s). In any case, proper acknowledgement of the original publication source must be made and any changes to the original work must be indicated clearly and in a manner that does not suggest the author's and or Publisher's endorsement whatsoever. Any other use of its content in any medium or format, now known or developed in the future, requires prior written permission of the copyright holder. 